\title{
Analysing the Mechanical Properties and Corrosion Phenomenon of Reinforced Metal Matrix Composite
}

\author{
Subramani Nanjan** (D), Janakiram Ganesh Murali \\ ${ }^{a}$ Karpagam College of Engineering, Department of Mechanical Engineering, Coimbatore, Tamil Nadu, India.
}

Received: December 12, 2019; Revised: March 02, 2020; Accepted: March 02, 2020

In this research, a Metal Matrix hybrid composite (MMHC) is prepared by reinforcing the following reinforcements like Graphite, Aluminium oxide, silicon carbide and boron carbide at a percentage of 4 and 5 is added with A6061. This preparation is carried out by using the stir casting method. In particular, the corrosion properties of the untreated A6061 reinforced composites samples were evaluated using in $3.5 \% \mathrm{NaCl}$ solution and immersion tests in $1 \% \mathrm{HCl}$ acidic water solution. The highest percentage of depicts the positive result. In addition to that the SEM, wear, hardness tests are carried out to bring out the positive impact of the newly prepared samples. In accordance with that the fundamental spotlight is given on Aluminum network composites on account of its novel blend of good corrosion protection, wear properties and outstanding mechanical properties.

Keywords: Al6061 Alloy, SiC, Particulates, Graphite, Wear, Stir casting, Corrosion, X-Ray Diffraction Analysis Test.

\section{Background}

Aluminum is the most well-known MMCs. The metal matrix composites (MMCs) are extremely alluring materials for a few applications. Generous advance in the improvement of light metal matrix composites has been accomplished in late decades, with the goal that they could be brought into the most critical applications. Aluminum matrix composites (AMCs) are the skillful materials in the mechanical world. Endeavors have been made to create aluminum metal matrix composites lately because of their low thickness, high quality, prevalent crawl protection; they have incredible potential in household appliances, sports kits, Car, marine and aviation applications $^{1,2}$.

Aluminum is the second most broadly utilized metal on the planet today after iron. It has a low density $(2.7 \mathrm{~g} / \mathrm{cc})$, excellent malleability, great corrosion protection, great thermal conductivity $(237 \mathrm{~W} / \mathrm{mK})$, low electrical resistivity (2.65*10-8 $\Omega . \mathrm{m})$ and great formability. It's Young's modulus is $70 \mathrm{GPa}$ and its Vickers hardness is 60 to $70 \mathrm{VHN}$. Aluminum has a melting point of $660.32^{\circ} \mathrm{C}$ and at high temperatures, the quality of aluminum diminishes. Be that as it may, the interest for aluminum and its combinations having a considerably higher quality is expanding. Al-matrix composites (AMCs) have been broadly utilized as a part of car and aviation businesses due to their great physical and mechanical properties ${ }^{3,4}$.

Many techniques are currently available to fabricate the metal matrix composites (MMCs), such as mechanical alloying, high-energy ball milling, spray deposition, powder metallurgy, stir casting, sintering, and various casting techniques. The powder metallurgy processing method cannot be used for bulk production of large and complex structural

*e-mail: subramanikcemech@gmail.com
(MMCs) components. The (MMCs) are thus manufactured by stir casting ${ }^{5,6}$.

The fluid metallurgy course or mix throwing process is the most normally utilized strategy to create the aluminum composites. This procedure is the easiest and can create more critical composite castings by this technique. It is economical for mass creation? ${ }^{7}$.

Aluminum-based metal matrix composites (AMCs) are broadly utilized as a part of car and airship applications because of their low thickness and simultaneous high wear protection, quality, erosion protection, solidness, and warm conductivity. Artistic reinforcement particulates like Sic, $\mathrm{B} 4 \mathrm{C}$, graphite, and $\mathrm{Al} 2 \mathrm{O} 3$ are the most regularly utilized and reinforced to produce a composite ${ }^{7,8}$.

In modern applications, most extreme parts are subjected to sliding movement and corrosion. Wear protection and corrosion protection must be provided by the essential parts. A few specialists explored wear conduct and erosion protection clay particulates exhibited by fortifying aluminum matrix composites ${ }^{9-13}$.

Electrochemical investigations show that Aluminium and AA5754 alloy have certain corrosion activity in a $1 \%$ acetic acid solution ${ }^{14}$. Results indicate that Aluminium has better corrosion resistance to the action of $1 \%$ acetic acid than its AA5754 alloy. The addition of ethanol solution of laurel oil in acetic acid decreases the values of corrosion current densities and increases the polarization resistance. Corrosion inhibition effect of laurel oil is confirmed by the SEM examination ${ }^{15}$.

Concerning the metal matrix composite, the choice of a matrix combination is directed by a few contemplations. Of specific significance is whether the composite is to be consistently or irregularly strengthened. The essential parts of the matrix compound are supposed to give effective 
exchange of load to the strands and to limit splits if fiber dissolved in the mixture happens thus the matrix amalgam for a ceaselessly strengthened (MMC) might be picked more for durability than for quality ${ }^{15-17}$.

On this premise lesser quality, more flexible, and harder matrix compounds might be used in constantly strengthened (MMCs). At that point, the decision concerning the choice of the matrix will be affected by the required composite quality; higher quality matrix combinations might be required. Extra contemplations in the decision of choosing the matrix incorporate potential fortification/matrix responses, either amid handling or in a benefit that may bring about debased composite execution; warm worries because of warm development crisscross between the fortifications and the network. MMCs prove higher flexibility and durability than pottery or CMCs, despite the fact that they have brought down pliability and strength than their individual unreinforced metal grid composites ${ }^{17}$.

\section{Aim}

The research goal is to produce a low-cost product similar to high-cost materials such as stainless steel, corrosion-resistant tungsten, and wear-resistant material. Nowadays composites play a vital role in all human life orientated things starting from life goods to entertainment goods. The aim of the research is to fabricate the water pipes and taps which can be used in the supply of hard water. So the initiative is taken to fabricate good composite materials which can be used to produce the product at a low cost to reach all the background of people around the world. Here in this research A6061, composite is prepared by mixing with the reinforcement (4\% to 5\%) like Graphite, aluminum oxide, silicon carbide and boron carbide with the help of stir casting method and various tests like Hardness, Wear, XRD, SEM and Corrosion tests are conducted to meet the requirement.

\section{Fabrication of samples}

The composite samples are prepared by using the Stir Casting Setup. Before adding the reinforcement the following steps are evolved in preparing the samples. The base metal A6061 is preheated up to $660^{\circ} \mathrm{C}$ in a separate preheater to

Table 1. Mechanical Properties of 6061

\begin{tabular}{lc}
\hline \multicolumn{1}{c}{ Ultimate tensile strength (MPa) } & $124 \mathrm{MPa}$ \\
\hline Yield strength (MPa) & $55.2 \mathrm{MPa}$ \\
\hline Properties Elongation (\%) & $25.0 \%$ \\
\hline Brinell Hardness at 500g load BHN-10mm Ball & 30 \\
\hline
\end{tabular}

attain the softening point by using cauldron heater. Oil is utilized as a fuel for warming up the furnace.

The mechanical properties of the A6061 is given in the Table 1.

Reinforced composite samples were prepared with varying weight percentage of reinforcement at $4 \%$ and $5 \%$. A6061 with 95\%, and 96\%,). (Graphite, aluminum oxide, silicon carbide and boron carbide) 2.5 to 20 microns size of the reinforcements were preheated at a predetermined temperature from $250^{\circ}$ to $550^{\circ}$ Celsius for 30 min keeping in mind the end goal to expel dampness or some other gases introduced inside the support ${ }^{18,19}$.

The preheating of likewise enhances the wettability of fortification with reinforcement matrix. Reinforcements are included as 4\% and 5\% structure with aluminum 6061 . The reinforcement's properties are given in the Table 2 .

The Preheating of reinforcements in heater is demonstrated as follows. Pre heated materials are included and stirred up with the liquid aluminium physically and heated up for a better appropriation with the aluminum matrix. The softening of the aluminum alongside boron carbide, aluminum oxide, graphite and silicon carbide is completed in the pot into the oil-let go into the heater and pouring of preheated fortifications in the matrix semisolid phase upgrades the wettability of the support and diminishes the molecule settling at the base of the cauldron.

Fortifications are poured physically with the assistance of a tapered container ${ }^{18,19}$. Mixing up the liquid aluminium with reinforcements at a steady rate which upgrades the uniform appropriation all through the matrix stage which is important to bordering the fortifications with the network material. While pouring the slurry in the mould the stream of the slurry is kept uniform to prevent from gas catching. At that point it is snappy extinguished with the assistance of air to lessen the settling time of the particles in the matrix. It is poured in the pattern sized of $20 \mathrm{~mm}$ diameter and a length of $120 \mathrm{~mm}$. In the wake of blending liquid slurry is filled in the coveted Mould with favoured measurements as mentioned above $(20 \mathrm{~mm} \times 100 \mathrm{~mm})$ as shown in the Figure 1 which would be encouraging for direct different tests on it $^{19}$. The corrosion characteristics of the aluminium composites were tested in the $\mathrm{NaCl}$ solution. The $\mathrm{NaCl}$ solution prepared by dissolving $30 \mathrm{gm} \mathrm{NaCl}$ in one litre water. The specimens for the tests were cut to size 20x20x $6 \mathrm{~mm}$, after which the sample surfaces were polished with emery paper starting from 120 grit down to 640 grit size ${ }^{19-21}$.

\section{Results and Discussion}

In this paper aluminum based metal matrix composites were produced by utilizing mix throwing strategy. Aluminum 6061 was chosen as matrix material Reinforcement materials were Graphite, Aluminum Oxide, Silicon Carbide and Boron Carbide. The example pieces were threw for (Graphite, aluminum oxide,

Table 2. Mechanical Properties of Graphite, Aluminium oxide, silicon carbide and boron carbide

\begin{tabular}{lccccccc}
\hline Reinforcements & Density gm/cc & Poisions Ratio & $\begin{array}{c}\text { Compressive } \\
\text { Strength } \\
\text { MPa }\end{array}$ & Hardness & $\begin{array}{c}\text { Elastic } \\
\text { Modulus } \\
\text { MPa }\end{array}$ & $\begin{array}{c}\text { Youngs } \\
\text { Modulus } \\
\text { GPa }\end{array}$ & $\begin{array}{c}\text { Tensile } \\
\text { Strength } \\
\text { MPa }\end{array}$ \\
\hline A12O3 & 3.69 & 0.21 & 2100 & 1175 & 300 & - & - \\
\hline Graphite & 1.80 & 0.17 & 2000 & 4000 & 1000 & 41 & 48 \\
\hline SIC & 3.1 & 0.14 & 3900 & 2800 & 410 & 261 & 261 \\
\hline B4C & 2.52 & 0.18 & 2583 & 3810 & 261 & 261 \\
\hline
\end{tabular}


silicon carbide and boron carbide) $4 \%$ and 5\% mixing with the A6061 after fortification after several tests like Brinell Hardness, Wear, XRD, SEM and Corrosion tests are conducted to meet the requirement were $l^{2} \mathrm{~d}^{21}$.

\section{1 hardness test}

Brinell hardness technique has high exactness, repeatability, and great portrayal. The Brinell hardness test is carried out to get to know the effect of the A6061 on the composites generated (Graphite, aluminium oxide, silicon carbide and boron carbide) in matrix material. The polished specimens were tested with the HBW micro durability tester and the values are depicted and shown below in Table $1^{16-21}$. here the higher percentage $(5 \%)$ gives a positive sign of hardness property in the prepared sample ${ }^{18-21}$. The values are depicted in the Table 3 .

The following hardness tests were performed, under the following conditions:

Ball Intender Size: $10 \mathrm{~mm}$

Ball Load : $500 \mathrm{~kg}$

Location : Cross section

Test : Brinell hardness Test.

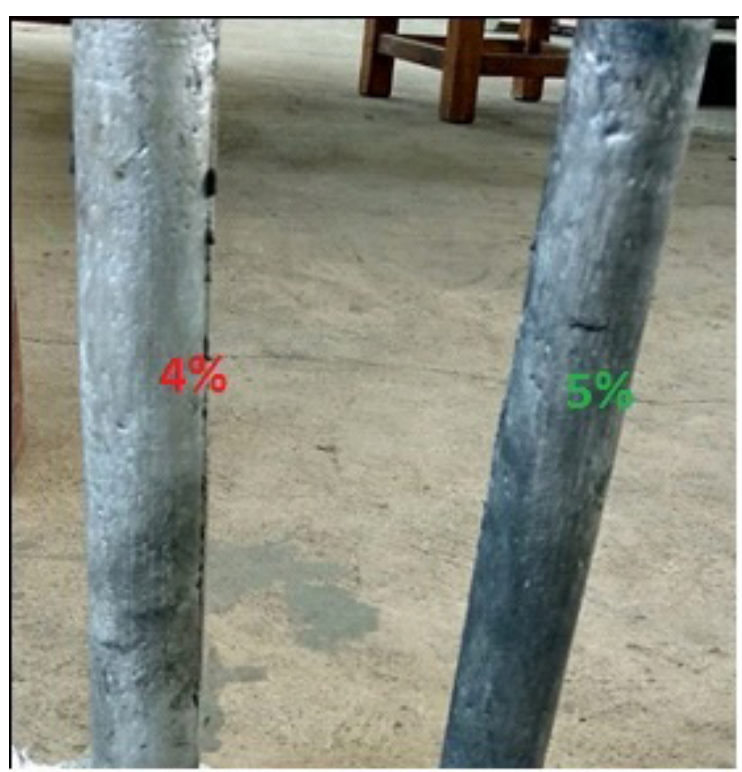

Figure 1. Prepared Samples- $4 \%$ and 5\%.

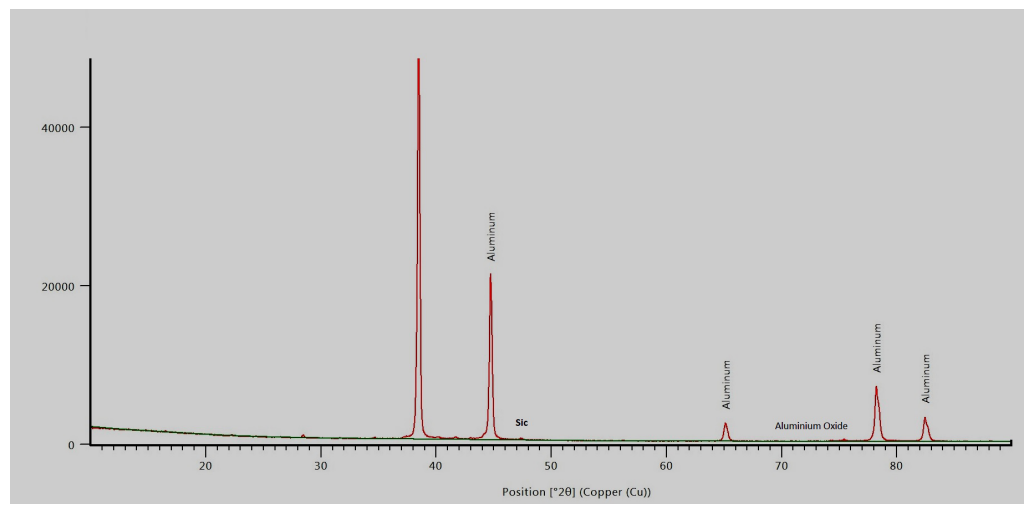

Figure 2. X-Ray Diffraction Analysis Pattern of 4\% of Reinforcement. (SiC, graphite, B4C, Al2O3)

\section{$4.2 x$-ray diffraction test}

$\mathrm{X}$-ray diffraction analysis $(\mathrm{XRD})$ results are confirmed the appearance of the $\mathrm{SiC}$, graphite, $\mathrm{B}_{4} \mathrm{C}, \mathrm{Al}_{2} \mathrm{O}_{3}$ particles in the alloy matrix as small peaks in XRD pattern as shown in Figure 2. Here the highest peak represents the A6061 material and the small peaks represents the reinforcement Sic and aluminium oxide.

$\mathrm{X}$-ray diffraction analysis $(\mathrm{XRD})$ results are confirmed the appearance of the $\mathrm{SiC}$, graphite, $\mathrm{B}_{4} \mathrm{C}, \mathrm{Al}_{2} \mathrm{O}_{3}$ particles in the alloy matrix as small peaks in XRD pattern as shown in Figure 3. Here the highest peak represents the A6061 material and the small peaks represents the reinforcement Sic, boron and aluminium oxide. The graphite is mixed in very less percentage so it is not depicted in the XRD. The graphite is added to improve the composite strength because of its nature that insoluble in water and it is an organic solvent and has a high melting point.

\section{2 wear test}

The volumetric wear loss of Al6061 combination and its composites is as shown in Figure 3. The impact of connected load on the wear conduct of Al6061 combination and its composites is shown in Figure 1. The volumetric wear loss is expanded as the typical load increments from $10 \mathrm{~N}$ to $50 \mathrm{~N}^{21}$,

Higher volumetric wear loss is found for matrix combination and the composites at higher burdens. At most extreme loads the temperature of sliding surface and stick surpasses the basic esteem. So as load increments on the stick at last there is an expansion in the volumetric wear loss of both the network compound.

The Brinell hardness tests explore the better performance of $5 \%$ mixture comparing with the $4 \%$. The variety of volumetric wear loss of the matrix compound Al6061 and its composites with $4 \%$ and $5 \%$ reinforcement particulates as a function of the applied load are shown in Figure 4. One may see that volumetric wear loss of the composites

Table 3. Hardness Test

\begin{tabular}{|c|c|c|c|c|}
\hline Trial No & $5 \%$ & Avg & $4 \%$ & Avg \\
\hline 1 & 50.3 & \multirow{3}{*}{49.7} & 38.1 & \multirow{3}{*}{39.5} \\
\hline 2 & 49.4 & & 40.2 & \\
\hline 3 & 49.2 & & 40.4 & \\
\hline
\end{tabular}

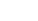




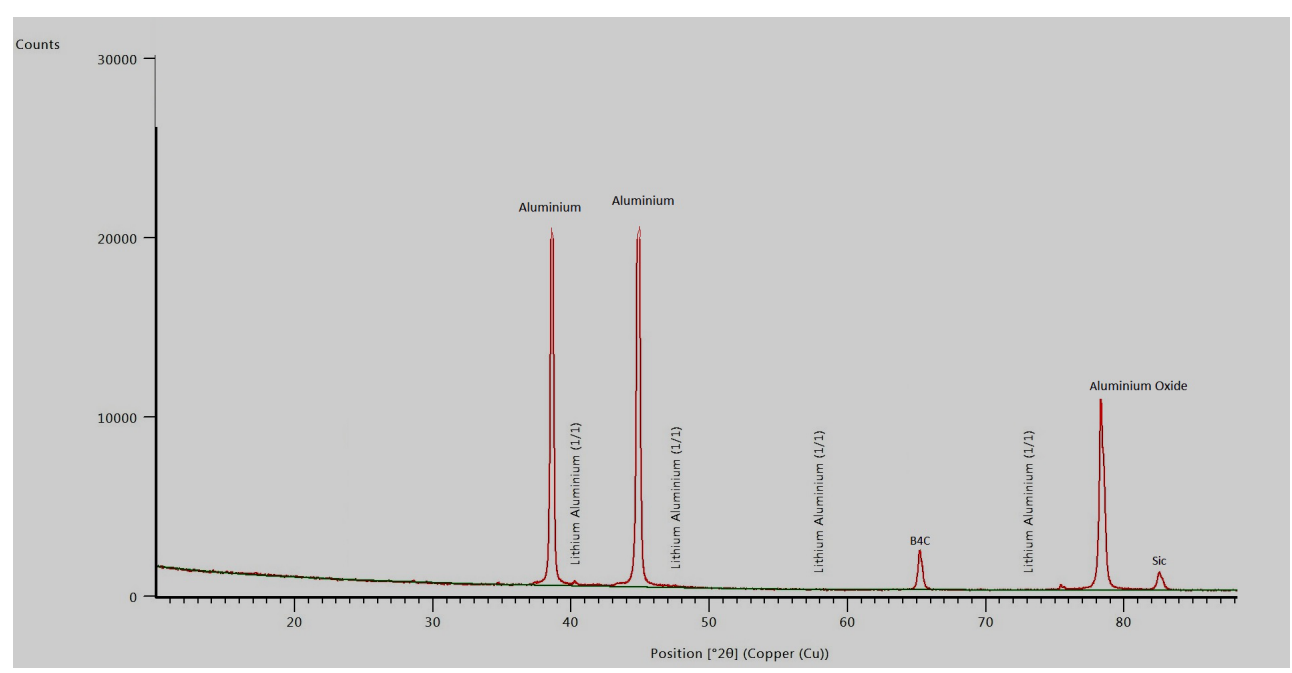

Figure 3. X - Ray Diffraction Analysis Pattern of 5\% of Reinforcement. (SiC, graphite, B4C, Al2O3)

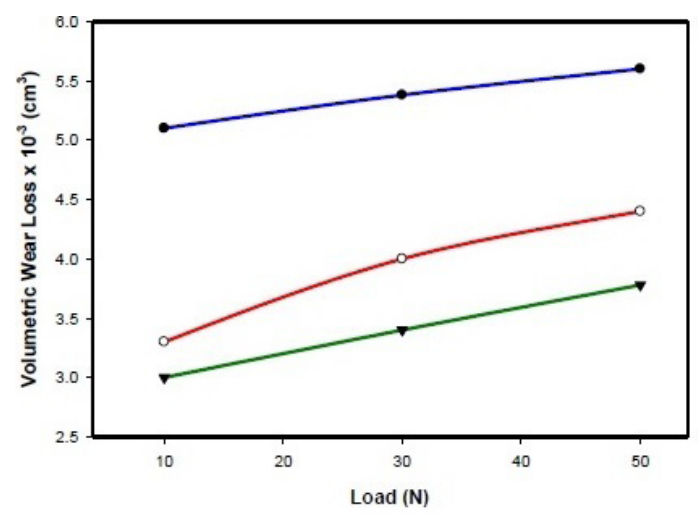

Figure 4. Volumetric wear loss of A16061 alloy and reinforcement at varying loads and $400 \mathrm{rpm}$ constant sliding speed (Blue - aluminium sample; Red-aluminium with $4 \%$ of reinforcement composite sample; Green - aluminum with $5 \%$ of reinforcement composite sample).

diminishes in matrix with $5 \%$ of reinforcement's particulates sample as against the aluminum sample. The change in the wear protection of the composites with $5 \%$ reinforcement particulates can be ascribed to the high hardness of $5 \%$ of reinforcement particulates which goes about as the obstruction to hinder the material loss. There was critical diminishing in volumetric wear loss in 4\% of reinforcement particulates composite sample. The volumetric wear loss of Al6061-5\% of reinforcement composite sample is lesser than A16061-4\% of reinforcement composite sample and A16061 sample.

The volumetric wear loss of A16061 and its composites is as shown in Figure 5. The impact of connected speed on the wear conduct of Al6061 combination and its composites is appeared in the Figure 4. The volumetric wear loss is rising as the typical load increments from 100RPM to 600RPM ${ }^{17-21}$. The wear rates of the prepared samples of $4 \%$ and $5 \%$ are shown in the Table 4.

Higher volumetric wear loss is seen for matrix combination and the composites at higher burdens. At most extreme speed the temperature of the sliding surface and stick surpasses

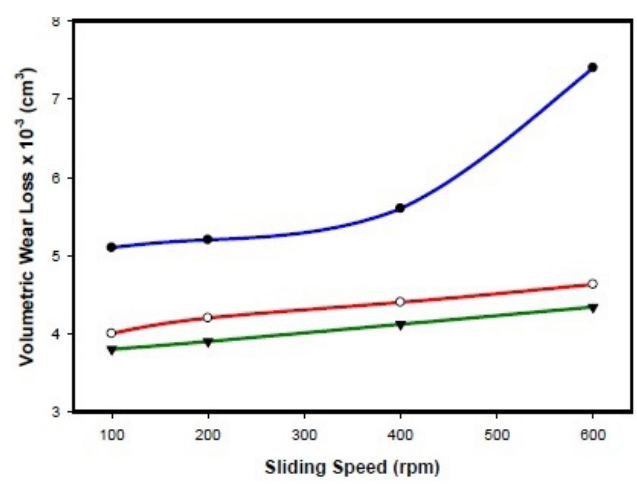

Figure 5. Volumetric wear loss of A16061 alloy and A16061 reinforcement composites at various sliding speeds and $50 \mathrm{~N}$ constant load; (Blue - aluminium sample; Red - aluminium with $4 \%$ of reinforcement composite sample; Green - Aluminium with $5 \%$ of reinforcement composite sample).

the basic esteem. So as speed rises on the stick at last there is an expansion in the volumetric wear loss of both the composite samples.

The variety of volumetric wear loss of the A6061 sample and its composites with $4 \%$ and $5 \%$ reinforcement composite samples are shown in Figure 4. One may see that the volumetric wear loss of the composites diminishes in the $5 \%$ of reinforcement composite sample. The change in the wear protection conferred by the composites with $5 \%$ of reinforcements can be ascribed to the high hardness of this sample which goes about as material loss. The volumetric wear loss of A16061-5\% of reinforcement composite sample is lesser than Al6061-4\% of reinforcement composite sample and Al6061 sample.

\subsection{Sem test}

The SEM images in the Figure 6 shows the 4\% reinforced particulates are scattered in the A6061 structure. In this black dots represents the boron, grey ash color represents the Sic and light grey represents the Graphite and the white surfaces point outs the aluminium oxide on the surface ${ }^{20,21}$. 
Table 4. Wear Test

\begin{tabular}{|c|c|c|c|}
\hline Sample & $\begin{array}{l}\text { Sliding Speed } \\
\text { (rpm) }\end{array}$ & Load (N) & $\begin{array}{c}\text { Volumetric Wear } \\
\text { Loss } x 10^{3}\left(\mathrm{~cm}^{3}\right) \\
\text { Avg }\end{array}$ \\
\hline \multirow{12}{*}{$4 \%$} & \multirow{3}{*}{100} & 10 & \multirow{3}{*}{3.82} \\
\hline & & 30 & \\
\hline & & 50 & \\
\hline & \multirow{3}{*}{200} & 10 & \multirow{3}{*}{4.12} \\
\hline & & 30 & \\
\hline & & 50 & \\
\hline & \multirow{3}{*}{400} & 10 & \multirow{3}{*}{4.15} \\
\hline & & 30 & \\
\hline & & 50 & \\
\hline & \multirow{3}{*}{600} & 10 & \multirow{3}{*}{4.22} \\
\hline & & 30 & \\
\hline & & 50 & \\
\hline \multirow{12}{*}{$5 \%$} & \multirow{3}{*}{100} & 10 & \multirow{3}{*}{3.67} \\
\hline & & 30 & \\
\hline & & 50 & \\
\hline & \multirow{3}{*}{200} & 10 & \multirow{3}{*}{3.69} \\
\hline & & 30 & \\
\hline & & 50 & \\
\hline & \multirow{3}{*}{400} & 10 & \multirow{3}{*}{3.85} \\
\hline & & 30 & \\
\hline & & 50 & \\
\hline & \multirow{3}{*}{600} & 10 & \multirow{3}{*}{4.10} \\
\hline & & 30 & \\
\hline & & 50 & \\
\hline
\end{tabular}

The SEM images in the Figure 7 shows the $5 \%$ reinforced particulates are scattered in the A6061 structure. In this black dots represents the boron, grey ash color represents the Sic and light grey represents the Graphite and the white surfaces point out the aluminium oxide on the surface.

\subsection{Corrosion test}

The corrosion properties of the $4 \%$ and $5 \%$ of reinforcement (Graphite/Sicp/B4C / $\mathrm{Al}_{2} \mathrm{O}_{3} / \mathrm{A} 6061$ ) composites. The analysis of corrosion behaviour of the reinforced A6061 samples was carried out at room temperature by means of $3.5 \% \mathrm{NaCl}$ solution and immersion tests in $1 \%$ $\mathrm{HCl}$ acidic water solution. Aluminium 6061 composites with $4 \%$ of reinforcement and $5 \%$ of reinforcement are shown in Figure 5 and Figure 8. The prepared composites are tested in $3.5 \% \mathrm{NaCl}$ solution and the results are given in the Table $5^{10}$. The percentage of weight loss in $5 \%$ reinforcement sample is better than the $4 \%$ of reinforcement sample. The micrographic image shows the surface change after the NACL test after 48 hours. The Optical micrographs images shows that there is no more changes and damages in the surface of the impressed samples the changes may occurs when it can be tested in the ECG tests in future ${ }^{20,21}$.

Optical micrographs (Mag:2.00 KX) showing surface topography after salt spray corrosion in $3.5 \% \mathrm{NaCl}$ solution at $125 \mathrm{X} \mathrm{Al} 6061$ with $4 \%$ of reinforcement at Figure 8.

Optical micrographs (Mag:2.00 KX) showing surface topography after salt spray corrosion in $3.5 \% \mathrm{NaCl}$ solution at $125 \mathrm{X} \mathrm{Al} 6061$ with 5\% of reinforcement at Figure 9

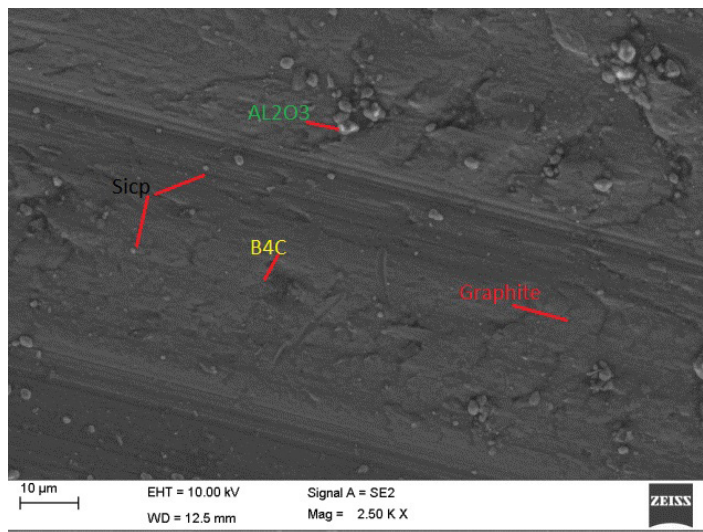

Figure 6. SEM Electron image of the 4\% Graphite/Sicp/B4C / A12O3/A6061 composites.

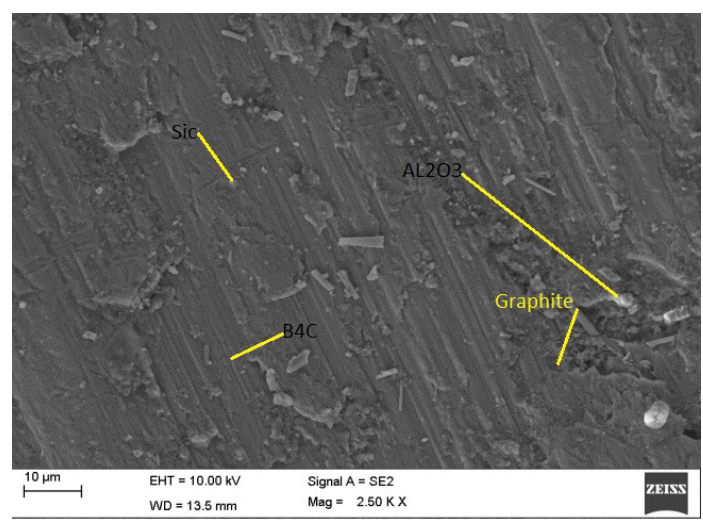

Figure 7. SEM Electron image of the 5\% Graphite/Sicp/B4C / A12O3/A6061 composites.

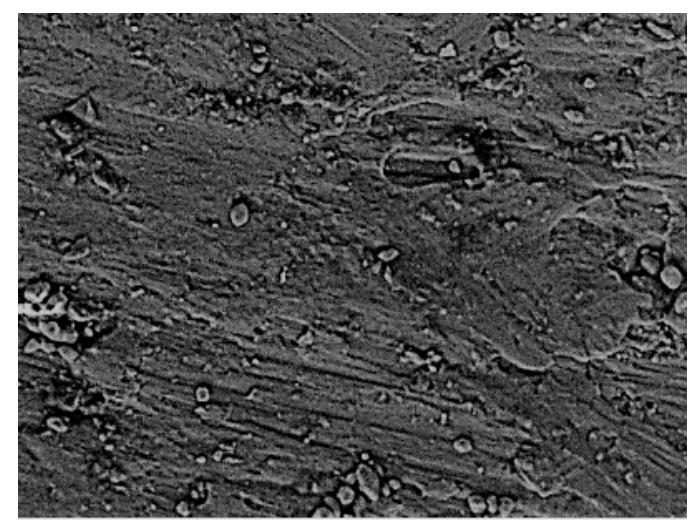

Figure 8. Corrosion rate of $4 \%$ with constant $\mathrm{A} 606196 \%$ of $\mathrm{NaCl}-3.5 \%$

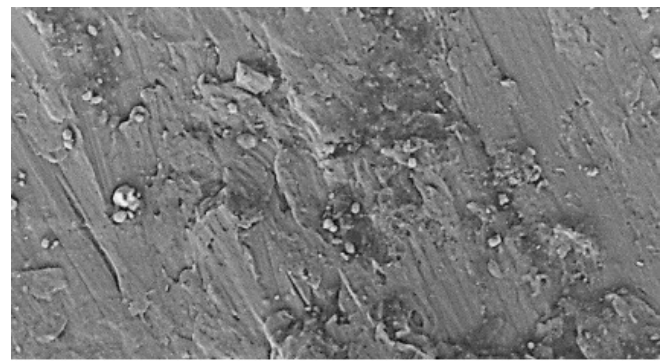

Figure 9. Corrosion rate of 5\% with constant A6061 95\% of NaCl-3.5\% 
Table 5. Wieght Loss

\begin{tabular}{|c|c|c|c|}
\hline Specimen & Percentage & Day & $\begin{array}{c}\text { Wt .Loss } \\
(\mathrm{gms})\end{array}$ \\
\hline \multirow{3}{*}{ I } & \multirow{9}{*}{$4 \%$} & 1 & 0.004 \\
\hline & & 2 & 0.006 \\
\hline & & 3 & 0.008 \\
\hline \multirow{3}{*}{ II } & & 1 & 0.0040 \\
\hline & & 2 & 0.0060 \\
\hline & & 3 & 0.0085 \\
\hline \multirow{3}{*}{ III } & & 1 & 0.006 \\
\hline & & 2 & 0.008 \\
\hline & & 3 & 0.0085 \\
\hline \multirow{3}{*}{ I } & \multirow{9}{*}{$5 \%$} & 1 & 0.006 \\
\hline & & 2 & 0.008 \\
\hline & & 3 & 0.01 \\
\hline \multirow{3}{*}{ II } & & 1 & 0.006 \\
\hline & & 2 & 0.008 \\
\hline & & 3 & 0.014 \\
\hline \multirow{3}{*}{ III } & & 1 & 0.006 \\
\hline & & 2 & 0.008 \\
\hline & & 3 & 0.015 \\
\hline
\end{tabular}

\section{Conclusion}

According to this research, Analysis of the corrosion and wear properties of reinforced metal matrix composites are extensively tried to analyze the properties of each sample prepared within less expenditure. Composite with $4 \%$ and $5 \%$ of reinforcement shows lower corrosion resistance than that of base alloy Aluminium 6061 in $3.5 \% \mathrm{NaCl}$ solution. The investigation made on fabrication and evaluation of wear behaviour Aluminium 6061 with $4 \%$ of reinforcement and Aluminium 6061 with 5\% of reinforcement metal matrix composite by the stir casting method has led to the following conclusions.

- Aluminium 6061 alloy and its composites have been effectively fabricated by stir casting method using two-step additions of particulates in the melt.

- The wear resistance of Aluminium 6061 alloy increased after the addition of $\mathrm{SiC}$ and graphite and $\mathrm{B} 4 \mathrm{C}$ and $\mathrm{Al} 2 \mathrm{O} 3$ particles.

- $\quad$ The volumetric wear loss is affected by load and sliding speed.

- The results obtained by tests in this work clearly designate that Aluminium has improved corrosion resistance to the action of 3.5 NACL solution than its A6061 alloy.

\section{References}

1. Prasad DS, Shoba C. Hybrid composites a better choice for high wear resistant materials. J Mater Res Techn. 2014;3:172-8.

2. Rama Rao S. Fabrication and mechanical properties of aluminium-boron carbide composites. Int J Mater Biomater Appl. 2012;2:15-8.
3. Nagaral M, Auradi V, Kori SA. Dry sliding wear behaviour of graphite particulate reinforced Al6061 alloy composite materials. Appl Mech Matl. 2014;592-594:170-4.

4. Zadra M, Girardini L. High performance low cost titanium metal matrix composites. Mater Sci Eng. 2014;608:155-63.

5. Vijay R, Elanchezhian C, Jaivignesh M, Rajesh S, Parswajinan C. Evaluation of mechanical properties of aluminium alloy alumina boron carbide metal matrix composites. Mater Des. 2014;58:332-8.

6. Shorowordi KM, Laoui T. Microstructure and interface characteristics of $\mathrm{B} 4 \mathrm{C} \mathrm{SiC}$ and $\mathrm{A} 12 \mathrm{O} 3$ reinforced $\mathrm{Al}$ matrix composites: a comparative study. In Proceedings of the 4th International Conference on Mechanical Engineering Dhaka Bangladesh; 2001; Dhaka, Bangladesh. USA: ICME; 2001. pp. $175-81$.

7. Hasim J, Looney L, Hashmi MSJ. Metal matrix composites production by the stir casting method. J Mater Process Technol. 1999;92:931-7.

8. Nagaral M, Attar S, Reddappa HN, Auradi V, Kumar SS, Raglu S. Mechanical behaviour of Al7025-B4C particulate reinforced composites. Appl Mech Eng. 2015;4:6.

9. Muthazhagan C, Gnanavelbabu A, Rajkumar K, Bhaskar GB. Corrosion behavior of aluminium-boron carbide-graphite composites, advanced materials research. Appl Mech Mater. 2014;591:51-4.

10. Rama Rao S, Padmanabhan G. Fabrication and mechanical properties of aluminium-boron carbide composites. Int J Materials and Biomater Appl. 2012;2(3):15-8.

11. Sharma $P$, Chauhan G, Sharma N. Comparative investigation of mechanical properties of aluminium based hybrid metal matrix composites. Int J Eng Res Appl (IJERA), 2014:5-9.

12. Surappa MK. Aluminium matrix composites: challenges and opportunities. Sadhana. 2003;28:319-34.

13. Ibrahim IA, Mohammed FA, Lavernia EJ. Particulate reinforce metal matrix composites. J Mater Sci. 1991;26:1137-56.

14. Hajizamani M, Baharvandi H. Fabrication and studying the mechanical properties of A356 alloy reinforced with Al2O3$10 \% \mathrm{Vol}$. ZrO2 nanoparticles through stir casting. Adv Mater Phys Chem. 2011;1:26-30.

15. Hashim J, Looney L, Hashmi MSJ. Particle distribution in cast metal matrix composites - part I. JMPT. 2002;123(2):251-7.

16. Radhia N, Subramanian R, Prasat SV. Tribological behaviour of aluminium/alumina/graphite hybrid metal matrix composite using taguchi's techniques. Journal of Minerals and Materials Characterization \& Engineering. 2011;10(5):427-43.

17. Sriram V, Velmurugan V, Vikram S, Sivakumar G. Friction welding of aluminium 7075 and boron carbide metal matrix composites. Int J Adv Res Basic Eng Sci Technol. 2017;3(38):32-44.

18. Nanjan S, Janakiram GM. Characteristics of A6061/(glass fiber $+\mathrm{AL} 2 \mathrm{O} 3+\mathrm{SiC}+\mathrm{B} 4 \mathrm{C})$ reinforced hybrid composite prepared through STIR casting. Adv Mater Sci Eng. 2019;(2019):1-12. https://doi.org/10.1155/2019/6104049.

19. Halambek J, Bubalo MC, Redovniković IR, Berković K. Corrosion behaviour of aluminium and AA5754 alloy in 1\% acetic acid solution in presence of laurel oil. Int J Electrochem Sci. 2014;9(10):5496-506.

20. Esquivel J, Murdoch HA, Darling KA, Gupta RK. Excellent corrosion resistance and hardness in Al alloys by extended solid solubility and nanocrystal line structure. Mater Res Lett. 2018;6(1):79-83.

21. Viceré A, Roventi G, Paoletti C, Cabibbo M, Bellezze T. Corrosion behavior of AA6012 aluminum alloy processed by ECAP and cryogenic treatment. Metals (Basel). 2019;9(4):408. 